\title{
Opportunistic parasitic infections in patients with human immunodeficiency virus/acquired immunodeficiency syndrome: A review
}

\author{
D. A. Laksemi1 ${ }^{1}$, L. T. Suwanti2,3(i), M. Mufasirin²,3iD, K. Suastika ${ }^{4}$ and M. Sudarmaja1(i)
}

1. Department of Parasitology, Faculty of Medicine, Udayana University, Bali, Indonesia; 2. Department of Parasitology, Faculty of Veterinary Medicine, Universitas Airlangga, Surabaya, East Java, Indonesia; 3. Institute of Tropical Disease, Universitas Airlangga, Surabaya, East Java, Indonesia; 4. Department of Internal Medicine, Faculty of Medicine, Udayana University, Bali, Indonesia.

Corresponding author: D. A. Laksemi, e-mail: srilaksemi@unud.ac.id

Co-authors: LTS: lucia-t-s@fkh.unair.ac.id, MM: mufasirin@fkh.unair.ac.id, KS: ksuas@unud.ac.id, MS: made_sudarmaja@unud.ac.id

Received: 22-11-2019, Accepted: 02-03-2020, Published online: 17-04-2020

doi: www.doi.org/10.14202/vetworld.2020.716-725 How to cite this article: Laksemi DA, Suwanti LT, Mufasirin M, Suastika K, Sudarmaja M (2020) Opportunistic parasitic infections in patients with human immunodeficiency virus/acquired immunodeficiency syndrome: A review, Veterinary World, 13(4): 716-725.

\begin{abstract}
The number of human immunodeficiency virus (HIV) cases increases annually, and Indonesia has become the country with the fastest HIV/acquired immunodeficiency syndrome (AIDS) epidemic spread among the five Southeast Asian countries. Indonesia entered the critical phase of HIV/AIDS infections after 5 out of the 33 provinces, namely, Papua, Jakarta, Bali, West Java, and East Java, reported HIV/AIDS epidemic since 2004. In AIDS pathophysiology and immune-suppression are severe, thus, opportunistic intestinal parasitic infections that cause diarrhea in HIV infection may be fatal. Several studies have suggested that Cryptosporidium parvum, Isospora belli, and Blastocystis hominis are the most common intestinal protozoan parasites categorized as AIDS associated illness. Diarrhea caused by parasites is considerably suspected in the cases of chronic and persistent diarrhea in adults, in an era of increasing HIV/AIDS cases nowadays. The present review highlights the current advances in etiologic agents of HIV/AIDS opportunistic infections among countries, epidemiology and prevalence, lifecycle, risk factors, examination methods, and treatment.
\end{abstract}

Keywords: epidemic, immune suppression, opportunistic infection, protozoa.

\section{Introduction}

Opportunistic parasitic infections are infections of parasite species that are mild or asymptomatic in immunocompetent people; however, in immunocompromised people they become fatal [1]. Opportunistic parasitic infections, including worms and protozoa, are neglected tropical diseases that are targeted by the sustainable development goals to be eliminated by $2030[2,3]$.

Human immunodeficiency virus (HIV) infection causes acquired immunodeficiency syndrome (AIDS), which is a complicated disease in humans, and suppresses the immune system [4,5]. Opportunistic parasitic infections are one of the most common health problems in patients with HIV/AIDS. The presence of opportunistic parasitic infections in HIV sufferers indicate that they are in the phase of AIDS. Most of these infections are severe, and often contribute to the death of infected individuals [4-7]. Thus, early detection and treatment need to be carried out to ensure adequate management [8-10].

Copyright: Laksemi, et al. Open Access. This article is distributed under the terms of the Creative Commons Attribution 4.0 International License (http://creativecommons.org/licenses/ by/4.0/), which permits unrestricted use, distribution, and reproduction in any medium, provided you give appropriate credit to the original author(s) and the source, provide a link to the Creative Commons license, and indicate if changes were made. The Creative Commons Public Domain Dedication waiver (http:// creativecommons.org/publicdomain/zero/1.0/) applies to the data made available in this article, unless otherwise stated.
The first case of HIV/AIDS in Indonesia was reported in Bali in 1987, while in Sulawesi it was reported in 2012 [11]. It is estimated that every minute, one Indonesian is infected with HIV/AIDS. The age group most affected is the productive age, i.e., 20-39 years, with a case fatality rate of $18.7 \%$ [11].

Among the opportunistic infections, parasites are the most common causative pathogens that affect the morbidity and mortality of patients infected with HIV/AIDS. Parasites can trigger an immune response to infect the respiratory tract, digestive tract, blood, brain, and other organs. The parasitic species that most often cause the opportunistic infections in the human body are Toxoplasma gondii, Cryptosporidium parvum, Isospora belli, Cyclospora cayetanensis, Microsporidia, Cryptococcus neoformans, Pneumocystis carinii or jiroveci, and Entamoeba [12-14].

Among the parasitic opportunistic infections (POIs), cryptosporidiosis, isosporiasis, and microsporidiosis are the main enteric POIs, and toxoplasmosis and leishmaniasis are the main systemic POIs reported in HIV-infected patients [2,4,6]. Another study described the opportunistic parasites C. parvum, Cyclospora cayetanensis, I. belli, and Microsporidia spp. as a common feature in HIV/AIDS patients, especially when the CD4+ T cell counts fall below 200 cells/ $\mu$ L [4].

Opportunistic infection has been categorized according to $\mathrm{CD} 4+$ counts as follows: 
Mycobacterium tuberculosis was found in all CD4+ counts; Coccidioidomycosis was in $\mathrm{CD} 4+$ counts $<250$ cells $/ \mathrm{mm}^{3}$; Pneumocystis jiroveci pneumonia and mucocutaneous candidiasis were in $\mathrm{CD} 4+$ counts $<200$ cells $/ \mathrm{mm}^{3}$; Histoplasma capsulatum was in CD4+ counts $<150$ cells $/ \mathrm{mm}^{3} ;$ C.neoformans, Cryptosporidiosis, Herpes simplex viruses, Microsporidiosis were in CD4+ counts $<100$ cells $/ \mathrm{mm}^{3}$; and $C$. neoformans, Cryptosporidiosis, and Cytomegalovirus, $T$. gondii, and Bartonellosis were in CD4+ count $<50$ cells $/ \mathrm{mm}^{3}$ [15].

UNAIDS data on the current HIV/AIDS situation have reported that globally 1.7 million people became newly infected with HIV by the end of 2018, 37.9 million people globally were living with HIV by the end of 2018, and almost 1 million people died from AIDS-related illnesses. Opportunistic parasitic infection is a major cause of morbidity and mortality worldwide; most of them are emerging diseases [11].

An understanding of parasites that cause opportunistic infections in HIV/AIDS is required, especially in the decades, where HIV has caused a huge burden on global wealth and health. Thus, early detection and prompt treatment can be established to reduce deaths due to HIV/AIDS.

This reivew presents an overview of the etiologic agents of opportunistic infections among countries, epidemiology and prevalence, lifecycle, risk factors, examination methods, and treatments.

\section{Clinically Relevant Intestinal Parasitic Infections}

Parasitic infections in the digestive tract remain a burden for people infected with HIV, even in the era of the use of antiretroviral therapy (ART) [16]. CD4+ count in HIV patients are risk factors for opportunistic parasitic infections with manifestations of diarrhea [4].

In AIDS with severe immunosuppression, commensal intestinal parasites become opportunistic, causing fatal prognostic diarrheal diseases in HIV patients. There are various species of parasites that cause diarrhea in HIV patients, such as C. parvum, Giardia lamblia, Microsporidia, and I. belli $[13,14]$. Some studies have reported that the most common intestinal parasitic species found in diarrhea experienced by HIV patients are Blastocyst spp., C. parvum, Microsporidia, S. stercoralis, and O. viverrini [17]. There are also parasites known as classical opportunistic agents, which are C. parvum, I. belli, C. cayetanensis, and Microsporidia [17].

A study reported that the introduction of the highly active anti-retroviral therapy regimen as the main treatment for HIV has led to the occurrence of immune reconstitution inflammatory syndrome in opportunistic parasitic infections such as C. parvum [12].

\section{Risk Factors for Opportunistic Parasitic Infection}

Risk factors for HIV/AIDS are man [7,18,19], unemployment, living in urban area, and marriage [19].
However, other studies have found that women, housewives, and trading are risk factors for HIV/AIDS [19].

In HIV/AIDS patients, the rate of a particular intestinal parasitic infection depends on the endemicity of the parasite in the community [7]. Intestinal parasites are widely distributed partly due to the low level of environmental and personal hygiene, fecal contamination of food and drinking water, and poor housing facilities [4]. Assessing current CD4+ cell count helps identify the status of intestinal parasite infection among HIV patients [20].

Risk factors associated with a higher prevalence of opportunistic parasitic infection among HIV patients were low CD4+ counts, persistent diarrhea, poor living conditions, and poor nutrition [20]. Another research reported ART status, CD4+ T-cell count, diarrhea, work status, and access to a toilet as the risk factors associated with a higher prevalence of intestinal parasites among HIV patients [19].

The association between the CD4+ T-cell count and intestinal protozoa infection has also been reported in the previous studies from Ethiopia, India, and Malaysia [4,18]. Stage of HIV/AIDS, CD4+ count, ART adherence, and hemoglobin level has also been reported as risk factors for opportunistic parasitic infections. CD $4+$ count $<200$ cells $/ \mu \mathrm{L}$ poses the greatest risk for opportunistic infection in HIV/AIDS patients [19].

Risk factors for $C$. cayetanensis are consumption of raw fruits and vegetables, drinking untreated water, swimming in rivers, contact with soil or animals, agricultural work, and poor hygiene [21]. Risk factors for C. parvum infection are non-Hodgkin's lymphoma, leukemia, lymphoproliferative disease, malnutrition, immunosuppressive drugs, cancers, and hemodialysis [22]. Risk factors for I. belli include lymphoblastic leukemia, adult T-cell leukemia, Hodgkin's disease, non-Hodgkin's lymphoma, lymphoproliferative disorders, renal transplant, and liver transplant [22].

Risk factors associated with Microsporidia infection include sexual relations between men, use of intravenous drugs, exposure to swampy water or irrigated areas, exposure to water with feces, and use of swimming pools and hot tubs, or contact with water [23]. Research shows that Microsporidia is often found in patients with malignancy and diabetes mellitus [22].

Intestinal parasitism during pregnancy may affect the health of pregnant women and their offspring [24]. However, only few studies have described the effects of intestinal parasitism on pregnancy outcomes [25]. Parasitic infection(s) during pregnancy have been associated with increased risk of pregnancy complications and adverse outcomes [25]. Low weight during pregnancy, poor fetal growth, low birth weight, and preterm birth are some of the consequences of intestinal parasitic infection during pregnancy [24].

One of the intestinal parasitic infections that had a significant consequence on pregnant women and their 
offspring was Blastocystis hominis, which recorded $15 \%(50 / 331)$ prevalence among pregnant women in Bogota, Colombia [24]. C. parvum and I. belli can be transmitted from human to human through anal-oral contact [26]. Another research stated that marital status was not implicated as a determinant of the occurrence of enteric protozoal infection among the study subjects [18].

\section{C. cayetanensis}

C. cayetanensis was first discovered in the form of blue-green algae, or coccidian-like body, or cyanobacterium-like body. This form of $C$. cayetanensis is without organelle, but has a membrane, and is larger in size than C. parvum. Traced phylogenetically, C. cayetanensis is closely related to the genus Eimeria [27].

C. cayetanensis oocysts are found in raspberries and water sources that have the potential to cause epidemics [27]. In the lifecycle of C. cayetanensis, oocysts must be in the form of sporocysts outside the human body before becoming infective [28]. The lifecycle of $C$. cayetanensis (Figure-1) starts from the release of oocysts in feces. After about 7 days of oocyst sporulation, it becomes an infective form. The sporocysts release sporozoites that infect the duodenum and jejunum, and then the sporozoites undergo asexual and sexual multiplication to produce oocysts that are non-sporulating in the host environment [27].

Patients suspected of having C. cayetanensis infection may present with symptoms of flu-like illness, diarrhea, anorexia, nausea, flatulence, fatigue, abdominal cramps, and mild fever accompanied by weight loss. Severe symptoms include ventricular dysrhythmia, biliary disease, Reiter syndrome, Guillain-Barre syndrome, ocular inflammation, sterile urethritis, and oligoarthritis [27].

Envirochek capsules and Hannifin filters can be used to get $C$. cayetanensis oocysts from water sources, while getting C. cayetanensis in the food can be performed through lectin (agglutination of wheat germ) coated with paramagnetic beads [29].

Parasitological diagnosis of $C$. cayetanensis is confirmed by finding spherical forms containing morula (oocyst) in the wet mount and stained preparations, including modified acid-fast stain, Giemsa, trichrome, Gram-chromotrope, and Kinyoun staining [27]. The method of fecal examination used for the diagnosis

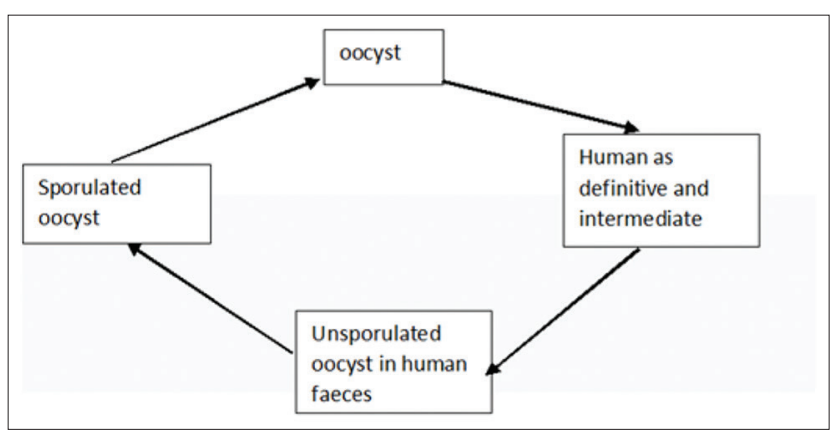

Figure-1: Life cycle of Cyclospora cayetanensis. of opportunistic parasitic infections includes direct saline, iodine wet mount, formalin-ether sedimentation concentration, and modified Ziehl-Neelsen [30]. Molecular techniques using the PCR method of internally transcribed spacer 2 of DNA were performed to obtain a segment of $116 \mathrm{bp}$ from the sample [27].

The first choice of treatment for C. cayetanensis infection is trimethoprim-sulfamethoxazole (TMP-SMX) $25 \mathrm{mg} / \mathrm{kg}$ body weight for 3 days, other alternative treatments are ciprofloxacin, norfloxacin, azithromycin, tinidazole, nalidixic acid, diloxanide furoate, and quinacrine [27].

\section{C. parvum}

C. parvum is an intracellular obligate parasite [31]. There are 31 species of $C$. parvum [32]. The parasite did not only cause diarrhea but it also manifested several symptoms in the lungs of HIV/AIDS patients [26].

Coccidian parasites (Cryptosporidium spp., I. belli, and Cyclospora spp.) are the most common enteric parasites in immunocompromised patients, which can cause severe, deadly diarrhea. The prevalence rate of cryptosporidiosis among diarrhea patients with HIV/AIDS is significantly higher than $10 \%$. Immunocompromised diarrhea tends to be chronic and causes increased morbidity and mortality in these patients [33].

Cryptosporidiosis is a zoonotic disease; livestock, wild animals, pets, and rats may play an important role as the reservoir. It can be transmitted from human to human through anal-oral contact or from humans to animals through fecal-oral [26]. Besides HIV/AIDS, individuals with immunodeficiency conditions, such as those who have received chemotherapy, organ, or bone marrow transplants, and malnutrition and diabetes mellitus patients are also prone to infection by C. parvum. Other risk factors for C. parvum infection are non-Hodgkin's lymphoma, leukemia, lymphoproliferative disease, immunosuppressive drugs, cancers, and hemodialysis [22].

The lifecycle of $C$. parvum (Figure-2) begins by ingestion of oocysts from contaminated water or food [34]. The parasite invades the intestinal epithelium, where it completes its lifecycle in the cytoplasm of the enterocyst. Unsporulated oocysts are excreted in feces and mature outside the host, where they develop into the infective sporulated oocysts [22]. C. parvum

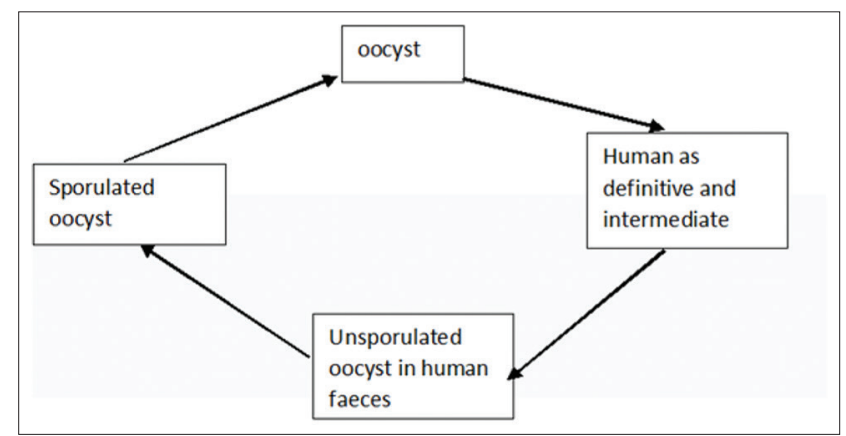

Figure-2: Life cycle of Cryptosporidium parvum. 
has a single host lifecycle that is asexual and sexual and occurs in the intestines of infected hosts [34].

Diarrhea caused by $C$. parvum in immunocompromised patients may be disseminated, thus causing increased mortality rate in HIV/AIDS [14]. C. parvum infection affects multiple organ functions, particularly the respiratory, pancreatic, and biliary tracts [35].

Microscopic examination is required to confirm the diagnosis of $C$. parvum infection. It can be performed by floatation, concentration, and Sheather's sugar solution [36]. Further examination can be performed through immunofluorescence assay (IFA), antigen (immunoassay), and polymerase chain reaction (PCR) [35,37]. Various rapid diagnostic tests (RDT) are available including Immunocard STAT, RIDA check, Quick check, Giardia-crypto duo-strip, and RDT, which generally combine the examination of C. parvum with G. lamblia [38].

There are no commercially available human vaccines for $C$. parvum, although numerous candidate attenuated and DNA vaccines have been identified [35,37]. Oocysts of C. parvum have acidfast (lipid-rich) walls, which are resistant to environmental insults and to gastrointestinal acids, proteases, and bile [37]. Prevention strategy must focus on proper hygiene and clean sanitary conditions to minimize Cryptosporidium outbreaks [35].

The pattern of opportunistic parasite species that is often found in people with HIV/AIDS in a country actually describes the opportunistic parasite species that exist in the country's natural environment. This is due to suppression of the immune system in people with HIV/AIDS, making the individual vulnerable to infections of opportunistic parasites in their environment.

Many research had been reported different protozoal agents that caused diarrheal disease in HIV/ AIDS. The opportunistic parasite infection pattern in each country is different (Table-1).

\section{Microsporidia}

Microsporidia is an intracellular obligate organism classified as eukaryotes because it has membranes, intra-cytoplasmic membrane systems, and chromosome separation in mitotic-spindles, and is closest to fungus because it contains chitin on the spore wall, but is more discussed as protozoa. Microsporidia has small, resistant spores; the phylum consists of 170 genera and 1300 species [39].

The lifecycle of Microsporidia consists of three phases, termed infective, proliferative, and sporogony $[39,40]$. Microsporidia can be transmitted through urine, soil, water, and food [41].

Microsporidia infection may affect muscles, intestines, gall bladder, liver, kidneys, eyes, brain, lungs, skin, and the nasal sinuses. Bowel Microsporidia most commonly occur in $30-50 \%$ of AIDS patients with chronic diarrhea [40].

The diagnosis of Microsporidia is determined by the use of several methods such as Giemsa, Gram, and/or Ziehl-Neelsen staining, to find spores containing polar filaments [39]. Touch preps and smears from biopsy, eye scraping, tissue specimens, and aspirations stained with Gram, Giemsa, or Trichrome can be identified in urine, stool, and duodenal fluid samples [39].

There are variations in Microsporidia, which help identify genus and species; they include the number of spores produced in sporogony, the way spores are produced, host interactions with parasites, morphological characteristics of developmental stages, nucleation, the place where infection occurs, and serological and molecular diagnosis [40].

Molecular examination methods for diagnosing Microsporidia include fluorescence, electron microscopy, ELISA, and Western blotting [39]. Immunofluorescence tests using the chitin binding Fluorochrome Uvitex 2B, Fungifluor, Calcofluor white, and Fungiqual $\mathrm{A}$ are available for detecting

Table-1: Different protozoal agents in diarrheal disease based on geographical regions.

\begin{tabular}{|c|c|c|c|}
\hline Parasite species & References & Published year & Country \\
\hline $\begin{array}{l}\text { Cryptosporidium parvum, Cyclospora cayetanensis, Isospora belli and } \\
\text { Microsporidium }\end{array}$ & [1] & 2016 & Cameroon \\
\hline $\begin{array}{l}\text { Cryptosporidium parvum, Isospora belli, Giardia lamblia, Entamoeba } \\
\text { histolytica, Iodamoeba butschlii }\end{array}$ & [3] & 2015 & India \\
\hline $\begin{array}{l}\text { Cryptosporidium parvum, Isospora belli, Cyclospora, Microsporidia, } \\
\text { Entamoeba histolytica }\end{array}$ & [4] & 2016 & India \\
\hline $\begin{array}{l}\text { Cryptosporidium parvum, Giardia lamblia, Leishmania tropica, } \\
\text { Pneumocystis carinii }\end{array}$ & [6] & 2016 & Egypt \\
\hline $\begin{array}{l}\text { Cryptosporidium parvum, Entamoeba histolytica, Isospora belli, Taenia, } \\
\text { Giardia lamblia }\end{array}$ & [7] & 2016 & India \\
\hline $\begin{array}{l}\text { Cryptosporidium spp., Cystoisospora belli, Cyclospora cayetanensis, } \\
\text { Giardia lamblia, Entamoeba histolytica, Blastocystis hominis, Microsporidia }\end{array}$ & [11] & 2015 & India \\
\hline $\begin{array}{l}\text { Blastocyst hominis, Cryptosporidium parvum, Microsporidia, Strongyloides } \\
\text { stercoralis, Opisthorchis viverrini, Entamoeba dispar, Giardia lamblia }\end{array}$ & [13] & 2014 & Laos \\
\hline Cryptosporidium parvum, Isospora belli, Blastocyst hominis & [14] & 2018 & Ethiopia \\
\hline $\begin{array}{l}\text { Cryptosporidium parvum, Isospora belli, Microsporidia, Cyclospora } \\
\text { cayetanensis, Giardia lamblia }\end{array}$ & [19] & 2015 & Ethiopia \\
\hline $\begin{array}{l}\text { Cryptosporidium parvum, Enterocytozoon bieneusi, Giardia lamblia, } \\
\text { Sarcocystis, Blastocyst hominis }\end{array}$ & [20] & 2013 & Iran \\
\hline
\end{tabular}


microsporidial infection. Monoplex PCR can also be used to detect Microsporidia [22].

\section{I. belli}

Cystoisospora belli is a synonym for I. belli, which belongs to the family Eimeridae, consisting of 15 species. Cystoisospora or I. belli is only found in humans, whereas other species such as Cystoisospora felis, Cystoisospora canis, and Cystoisospora suis are present in animals [42].

Coccidian parasites (Cryptosporidium spp., I. belli, and Cyclospora spp.) are the most common enteric parasites in immunocompromised patients, which can cause severe, deadly diarrhea [33]. Of the eight chronic cases of isosporiasis persisted with standard antimicrobial therapy and secondary prophylaxis, four patients died, two remained symptomatic, and two recovered. Mortality from $I$. belli infection in HIV/AIDS is high, especially at low CD4 + levels [43].

Human-to-human transmission is impossible in I. belli infection as the formation of an infective stage requires an external environment. The lifecycle of I. belli (Figure-3) begins when oocysts released in the non-infective $I$. belli become infective after being outside the body or in the environment. I. belli is not a zoonotic disease because humans are the only definitive host; there is no intermediate host. Transmission occurs through anal-oral contact, contaminated water, and food [44].

The method of the examination for diagnosing I. belli is the same as that for C.parvum [44]. The treatment for I. Belli infection is TMP/SMX regiment [44]. The low prevalence and variations of isosporiasis could be due to the wide use of anti-opportunistic infection medications, ART, and geographic differences. Furthermore, it has been suggested that co-trimoxazole prophylaxis given for other infections in AIDS cases, and the low number of oocysts excreted is possible explanations for the observed low prevalence of isosporiasis [18].

\section{Sarcocystis}

HIV infection has altered both the epidemiology and outcome of enteric opportunistic parasitic infections. A study in Iran showed that the most common opportunistic and non-opportunistic pathogens

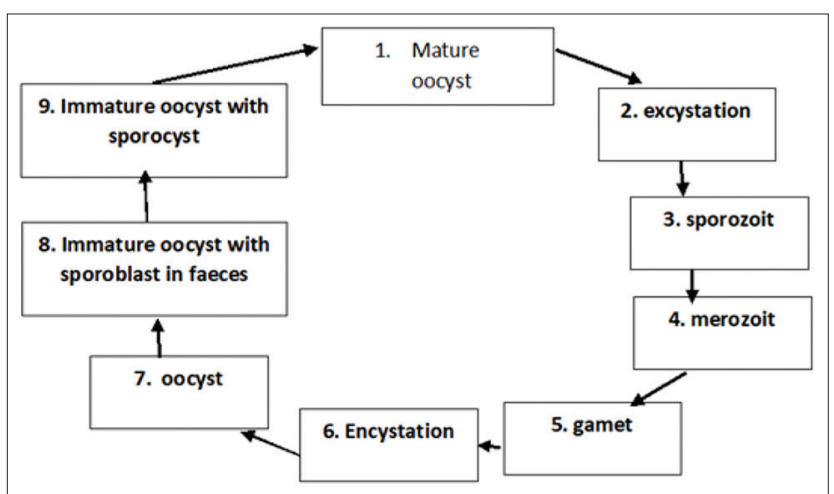

Figure-3: Life cycle of Isospora belli. were $C$. parvum, followed by E. bieneusi, G. lamblia, Sarcocystis spp., and B. hominis [41]. Research in Malaysia also showed that Sarcocystis is a potentially infectious disease in travelers [45]. Infection with intestinal sarcocystosis causes a self-limiting disease characterized by nausea, abdominal pain, and diarrhea in immunocompetent persons whereas in HIV/AIDS patients it could cause myopathy [46].

Sarcocystis was first discovered in pork meat. In the beginning, it was named sarcosporidium as the culture media produced hyphae and mycelium before clearer structure could be seen microscopically. Sarcocystis species infection is rare [45].

The morphology of Sarcocystis oocyst resembles that of $I$. belli, while the sporocysts are larger than those of C. parvum [42]. Intermediate hosts of Sarcocystis are herbivores, mammals, reptiles, birds, fish, and humans. The definitive host contains intestinal stage parasites, which vary from carnivorous animals to humans [44]. Transmission of Sarcocystis infection occurs from the consumption of raw meat containing the sarcocysts or ingesting water or food contaminated with the oocysts [44].

Sarcocystis hominis is found in cattle, while S. suihominis is found in pigs $[44,45]$. The clinical manifestation of the infection is generally asymptomatic; symptoms may involve diarrhea, abdominal pain, and weight loss [44]. Other symptoms include fever, headache, myalgia, and myositis in severe conditions caused by the development of intramuscular cysts. Clinical symptoms caused by $S$. suihominis are more severe than those of $S$. hominis. Presumptive diagnosis for Sarcocystis is done by taking into account any history of recent travel to tropical areas, increased serum enzymes, and eosinophilia [45].

The method of the diagnosis for Sarcocystis is similar to that for C. parvum and I. belli; muscle biopsy needs to be performed when myalgia is found [44]. The treatment of $S$. suihominis and $S$. hominis infections is with SMX-TMT, otherwise symptoms in the muscles are essentially treated with anti-inflammatory drugs [45].

\section{B. hominis}

B. hominis is a eukaryotic, cosmopolitan parasite, infecting various animals ranging from birds, pigs, horses, amphibians, reptiles, to insects [47]. B. hominis, which is commonly found in the intestinal tract, can lead to gastrointestinal symptoms such as diarrhea, nausea, abdominal pain, vomiting, and bloating. The prevalence of $B$. hominis is $1.5-10 \%$ in developed countries, where it can cause deterioration of health in immune-compromised patients. B. hominis can be harmful to HIV-positive patients or organ-transplant patients who receive immunosuppressive agents [48].

The morphology of $B$. hominis varies between the cystic, vacuolar, multi-vacuolar, granular, and amoeboid forms. The pathognomonic characteristic of $B$. hominis is the large centralized vacuoles [47]. The protozoa are commonly found in individual feces 
without any symptoms, which show this parasite is of low pathogenicity [47].

$B$. hominis infects the cecum and colon. The prevalence of $B$. hominis ranges from 1.6 to $50 \%$. The prevalence of $B$. hominis infection was $72 \%$ in people with HIV/AIDS in Indonesia [47]. Research in the United States and Paris showed that $B$. hominis infections were more frequent compared to Entamoeba histolytica, G. lamblia, and C. parvumin HIV/AIDS patients [49].

The lifecycle of $B$. hominis starts from the solid-walled cysts in feces, infects the host to proceed to asexual multiplication, becomes vacuolar form, arranges a multi-vacuolar or amoeboid form, and becomes a pre-cyst. Further development of the pre-cyst can be a thick- or thin-walled cyst. Thin-walled cysts play a role in the auto-infection process, while thick-walled ones will be released in the stool and are the infective form later in fecal-oral or external transmission $[47,49]$.

Preferred therapies for $B$. hominis infections are emetin, furazolidone, metronidazole, and TMP-SMX. Metronidazole at a dose of 250-750 mg 3 times a day for 5 days or $2 \mathrm{~g} /$ day for 5 days is a therapeutic regimen to treat $B$. hominis infection in immunocompetent patients with symptoms of diarrhea, abdominal pain, and nausea [47]. In HIV/AIDS patients, treatment with furoximin becomes the choice to eradicate $B$. hominis [47]. Another study using a 0.5-1 g metronidazole regimen for 7-10 days, showed relieve of symptoms accompanied by a diminished concentration of B. hominis in feces [47].

\section{C. neoformans}

C. neoformans is a fungus, which is commonly found in urban areas. It may infect immunocompromised individuals who ingest the spores. In individuals with adequate immune systems, $C$. neoformans vars gatti is generally asymptomatic, however, in immunocompromised individuals, it becomes a major cause of fatal neurological symptoms, such as meningitis [50]. Risk factors for $C$. neoformans infection include patients undergoing organ transplants and other long-term immunosuppressive therapy [50,51]. Capsules, melanin, and urease phospholipase activity are the virulence factors of $C$. neoformans, which play an important role in environmental survival [51,52]. C. neoformans can cause chronic diarrhea in non-HIV infected patients. Chronic diarrhea caused by $C$. neoformans is less frequent, and clinical suspicion is required to determine diagnosis [53].

The main treatment for infection caused by C. neoformans is amphotericin as a secondary metabolite of Streptomyces nodosus. For the treatment of C. neoformans infection in HIV/AIDS patients, HIV protease inhibitor such as indinavir may be used [50].

\section{Diagnosis and Supporting Examination for Detecting Diarrhea-causing Parasites in HIV/AIDS Patients}

The examination methods for diagnosing intestinal parasitic infections in patients with HIV are selected based on the organism. The methods include formalin-ethyl concentration technique for protozoa and worms, modified acid-fast staining for coccidian that cause classical opportunistic infections (C. parvum, I. belli, C. cayetanensis, and S. hominis), whereas microspora examination is done with Trichrome staining $[17,18]$. Stool samples were examined in iodine preparation for the detection of protozoan oocysts and cysts. Permanent stained smears are performed with modified Ziehl-Neelsen staining (Cold Method) for the detection of oocysts of Cryptosporidium, Isospora, and Cyclospora [10]. Simple direct, concentrated, and stained smear examination of stool can help in the identification of enteric parasites in majority of patients [7].

\section{Diagnostic Molecular Methods for Opportunistic Parasitic Infections}

After the discovery of nucleic acid-based detection, the multiplex real-time PCR method has been applied in diagnosing intestinal parasites in the Netherlands. The advantage of this method of detection and quantification of parasite-specific DNA are that it is very sensitive, thus increases detection of intestinal parasites, namely, Giardia lamblia and Cryptosporidium spp. [54]. Monoplex PCR is used to detect Microsporidia and Cryptosporidium, whereas multiplex PCR is used for G. lamblia, Cryptosporidium, Dientamoeba fragilis, and E. histolytica [39]

Molecular diagnostic methods for $C$. parvum include lateral flow immunoassays, immunochromatographic assays, and direct fluorescent antibody tests. A TaqMan PCR assay targeting, the 18S ribosomal DNA (rDNA) has been found to detect Cryptosporidium species [22]. Molecular diagnostic methods for $C$. cayetanensis include autofluorescence under UV, epifluorescence microscopy, and DNA amplification using PCR. A real-time PCR targeting, the internal transcribed spacer two regions of the rRNA gene have also been used to examine $I$. belli DNA in fecal samples [22].

The PCR method is useful for determining Microsporidia species because there are 14 Microsporidia species. In addition to the PCR method, the immunofluorescent-antibody test has the same sensitivity as PCR [22]. Sarcocystis can be detected using transmission electron microscopy [55]. The method of PCR- restriction fragment length polymorphism was used to amplify approximately $900 \mathrm{bp}$ fragment at the 18S rRNA (SSU) gene, of which the restriction enzyme BclI was used for the identification of Sarcocystis species in Iran [56].

The diagnosis of $B$. hominis can be made using the methods of conventional, phase-contrast, and electron microscopies, cultivation, sero-diagnosis, and using molecular methods [57]. Blastocystis exhibits extensive genetic diversity, and this has been documented using numerous molecular techniques [22]. 
PCR was performed using seven primer pairs targeting the SSU rDNA gene, and sequencing have been used to detect $B$. hominis in Iran. Multiplex PCR using two primer sets were tested (CN4-CN5) and the multiplex $\mathrm{CNa} 70 \mathrm{~S}-\mathrm{CNa} 70 \mathrm{~A} / \mathrm{CNb} 49 \mathrm{~S}-\mathrm{CNb}-49 \mathrm{~A}$ that amplified a specific product for $C$. neoformans and another for C. gattii are [58] already established [59].

Molecular diagnosis methods for the identification of Cyclospora oocysts are hampered by the lack of animal models and limited DNA sequence data. Techniques for fingerprint analysis and genotype discrimination are not available for $C$. cayetanensis; therefore, identification using a microscope is still frequently used [21]. Microsporidia are difficult to detect because of their small size, their slowly infecting properties, and sometimes asymptomatic infection. Immunoblot, ELISA, and IFA using monoclonal and polyclonal antibodies also help serological examination for Microsporidia characterization. However, serological testing cannot be relied on in people with HIV because of lack of immunity [23].
Simple India ink examination of the CSF has a $70-90 \%$ sensitivity and cases that are negative on the India ink test, can be reliably diagnosed by detection of cryptococcal antigen. Antigen detection based on latex agglutination although sensitive and specific were never widely available in high-burden, resource-limited settings. In the context of limited resources, development of a lateral flow assay (LFA; manufactured by IMMY) has been a major advancement. A second, semi-quantitative, lateral flow test is now in development by Biosynex and Institut Pasteur in Paris, France [60].

The association between intestinal parasitic infections and HIV infection has been well documented in many research $[2,4,7,10,13,14,16,18,22,31,34,46,61]$. The prevalence of intestinal parasitic infections was varied depending on geographic and other factors such as CD4+ count, ART, prophylaxis, hygiene, and sanitation (Table-2) [1,4,7,9,11,12,14,19,33]. Different examination methods that have been used to investigate intestinal parasitic infections also

Table-2: Prevalence, risk factors, and examination methods of opportunistic parasitic infection in HIV/AIDS patients based on geographical regions.

\begin{tabular}{|c|c|c|c|c|c|}
\hline $\begin{array}{l}\text { Prevalence } \\
\text { of intestinal } \\
\text { parasitic infection }\end{array}$ & Risk factors & Examination methods & References & $\begin{array}{l}\text { Published } \\
\text { year }\end{array}$ & Country \\
\hline $30.6 \%$ & CD 4 count $<200$ cell $/ \mu \mathrm{l}$ & $\begin{array}{l}\text { Wet mount, formol-ether } \\
\text { sedimentation and modified } \\
\text { Ziehl-Neelsen techniques }\end{array}$ & [19] & 2015 & Ethiopia \\
\hline $32.5 \%$ & CD 4 count $<200$ cell $/ \mu l$ & $\begin{array}{l}\text { Direct wet-mounts (normal } \\
\text { saline, Lugol's iodine), formol- } \\
\text { ether concentration, modified } \\
\text { Ziehl-Neelsen, modified } \\
\text { trichrome staining }\end{array}$ & {$[11]$} & 2015 & India \\
\hline $45 \%$ & CD 4 count $<200$ cell $/ \mu l$ & $\begin{array}{l}\text { Direct microscopy by saline } \\
\text { wet mount, iodine wet mount, } \\
\text { modified Ziehl-Neelsen (ZN) }\end{array}$ & [7] & 2016 & India \\
\hline $45 \%$ & $\begin{array}{l}\text { CD } 4 \text { count } 200-500 \\
\text { cell/ } \mu \text { l, Health education } \\
\text { regarding personal } \\
\text { hygiene, regular } \\
\text { de-worming }\end{array}$ & $\begin{array}{l}\text { Direct wet mount, formalin } \\
\text { ether concentration, } \\
\text { modified Ziehl-Neelsen (ZN) }\end{array}$ & [33] & 2016 & Laos \\
\hline $49 \%$ & $\begin{array}{l}\text { Age group } 20-30 \text { years, } \\
\text { geographis, personal } \\
\text { hygiene, sanitary } \\
\text { habits, method of stool } \\
\text { examination, immune } \\
\text { status }\end{array}$ & $\begin{array}{l}\text { Iodine, saline, formalin ether } \\
\text { concentration }\end{array}$ & [4] & 2016 & India \\
\hline $\begin{array}{l}\text { pre ART } 84.6 \% \text {, } \\
\text { ART } 82.3 \%\end{array}$ & CD 4 count $<200$ cell $/ \mu l$ & $\begin{array}{l}\text { Wet mount, Iodine mount, } \\
\text { Katokatz, formalin ether } \\
\text { concentration, modified Ziehl- } \\
\text { Neelsen (ZN), Modified field } \\
\text { staining }\end{array}$ & [1] & 2016 & Cameroon \\
\hline $85 \%$ & CD 4 count $<200$ cell $/ \mu \mathrm{l}$ & $\begin{array}{l}\text { Direct wet mount (saline } \\
\text { and Lugol's Iodine), formalin } \\
\text { ether concentration, modified } \\
\text { Ziehl-Neelsen (ZN), Trichrome } \\
\text { staining, Iron Hematoxylin } \\
\text { staining }\end{array}$ & [12] & 2016 & India \\
\hline $28.18 \%$ & $\begin{array}{l}\text { CD } 4 \text { count }<500 \text { cell } / \mu \mathrm{l}, \\
\text { Presence of domestic } \\
\text { animals, poor sanitation }\end{array}$ & $\begin{array}{l}\text { Direct wet mount, formol- } \\
\text { ether sedimentation modified } \\
\text { Ziehl-Neelsen }\end{array}$ & [14] & 2018 & Ethiopia \\
\hline $26.4 \%$ & $\begin{array}{l}\text { CD } 4 \text { count }<200 \text { cell/ } \mu \mathrm{l} \text {, } \\
\text { ART, Trimethoprim- } \\
\text { sulfamethoxazole (TS) } \\
\text { prophylaxis }\end{array}$ & $\begin{array}{l}\text { Direct wet mount, Ritchie } \\
\text { and modified Ziehl-Neelsen } \\
\text { techniques, Coproantigen }\end{array}$ & [9] & 2017 & Mozambique \\
\hline
\end{tabular}

ART=Antiretroviral therapy, HIV=Human immunodeficiency virus, AIDS=Acquired immunodeficiency syndrome 
Table-3: Diagnosis methods based on modern molecular biology of opportunistic parasitic infection.

\begin{tabular}{|c|c|c|}
\hline Parasite species & Molecular biology based methods of diagnosis & References \\
\hline Cryptosporidium parvum & $\begin{array}{l}\text { Monoplex PCR } \\
\text { Multiplex PCR } \\
\text { Lateral Flow Immunoassay, Immunochromatographic assay, } \\
\text { Direct Fluorescent Antibody Test, TaqMan PCR }\end{array}$ & $\begin{array}{l}{[39]} \\
{[54]} \\
{[22]}\end{array}$ \\
\hline Cyclospora cayetanensis & Autofluorescent under UV EpiFluorescent, PCR & {$[22]$} \\
\hline Isospora belli & PCR, Real time PCR & [22] \\
\hline Blastocyst hominis & Phase contrast electron microscopy, serodiagnosis, PCR & {$[57,59]$} \\
\hline Sarcocystis & $\begin{array}{l}\text { Transmission Electron Microscopy } \\
\text { PCR-RFLP }\end{array}$ & $\begin{array}{l}{[55]} \\
{[56]}\end{array}$ \\
\hline Microsporidia & $\begin{array}{l}\text { Immunofluorescent Test, IFAT } \\
\text { Monoplex PCR } \\
\text { Immnuoblot, ELISA, IFAT }\end{array}$ & $\begin{array}{l}{[22]} \\
{[39]} \\
{[23]}\end{array}$ \\
\hline Cryptococcus neoformans & Multiplex PCR & {$[58]$} \\
\hline
\end{tabular}

$\mathrm{PCR}=$ Polymerase chain reaction, $\mathrm{RFLP}=$ Restriction fragment length polymorphism, IFAT=Immunofluorescence antibody test

influenced the prevalence of the diseases. Various molecular diagnosis methods have been used for detection of opportunistic parasitic infections (Table-3) [22,23,39,54,55,56,57,58,59].

\section{Treatment for Opportunistic Parasitic Infections}

The treatment for $B$. hominis is metronidazole [57]. The drugs of choice for cryptosporidiosis include paromomycin, azithromycin, and nitazoxanide [22]. Effective treatment for C. cayetanensis infection is TMP-SMX; the alternative therapy is nitazoxanide, or ciprofloxacin. Treatment for I. belli infection is co-trimoxazole for 7-10 days [22]. Albendazole has been shown to be effective in treating infections caused by Microsporidia. Other drugs of choice for Microsporida include nitazoxanide and furazolidone [22]. Amphotericin B plus flucytosine rapid clearance is used for C. neoformans [60].

\section{Conclusion and Future Perspective}

Opportunistic parasitic infections are the most common health problems in patients with HIV/AIDS. Opportunistic intestinal parasitic infections will increase in the future due to the increasing incidence of HIV/AIDS in the population. However, early detection, using molecular diagnosis methods, of intestinal parasitic infections in HIV seropositive patients, appropriate initial treatment in new cases, and maintenance therapy in chronic cases will improve the quality of life of people infected with HIV.

\section{Authors' Contributions}

DAL had the idea, compiled, managed team and source, also wrote the manuscript, LTS, MM, and MS provided journal content, and prepared the manuscript. KS drafted and finalized the manuscript. All authors read and approved the final manuscript.

\section{Acknowledgments}

We would like to thank Ketut Suyasa, Dean of the Faculty of Medicine at Udayana University,
Bali, for supporting and encouraging this paper to be published.

\section{Competing Interests} interests.

The authors declare that they have no competing

\section{Publisher's Note}

Veterinary World remains neutral with regard to jurisdictional claims in published institutional affiliation.

\section{References}

1. Al-Qobati, S.A., Al-Nabehi, B.A., Mohamad, A.A., Al-Nabbhi, A.S. and Al-Kadi, M.A. (2018) Enteric protozoal infections among immunocompromised and immunocompetent people, Sana'a Town, Yemen. EC Microbiol., 14.12(1): 837-843.

2. Cerveja, B.Z., Tucuzo, R.M., Madureira, A.C., Nhacupe, N., Langa, I.A., Buene, T., Banze, L., Funzamo, C. and Noormahomed, E.N. (2017) Prevalence of intestinal parasites among HIV infected and HIV uninfected patients treated at the $1^{\circ}$ De Maio health centre in Maputo, Mozambique. EC Microbiol., 9(6): 231-240.

3. Yoshimura, K. (2017) Current status of HIV/AIDS in the ART era. J. Infect. Chemother., 23(1): 12-16.

4. Nsagha, D.S., Njunda, A.L., Assob, N.J.C., Ayima, C.W., Tanue, E.A., Kibu, O.D. and Kwenti, T.E. (2016) Intestinal parasitic infections in relation to $\mathrm{CD}^{+} \mathrm{T}$ cell counts and diarrhea in HIV/AIDS patients with or without antiretroviral therapy in Cameroon. BMC Infect. Dis., 16(9): 1-10.

5. Shenoy, N., Ramapuram, J.T., Shenoy, A., Ahmed, J. and Srikant, N. (2017) Incidence of opportunistic infections among HIV-positive adults on highly active antiretroviral therapy a teaching hospital, India: Prospective study. J. Int. Assoc. Provid. AIDS Care., 16(3): 309-283.

6. Patel, S.D., Javadekar, T.B. and Kinariwala, D.P. (2015) Enteric opportunistic parasitic infections in HIV seropositive patients at tertiary care teaching hospital. Natl. J. Med. Res., 5(3): 190-194.

7. Rao, R.P. (2016) Study of opportunistic intestinal parasitic infections in HIV seropositive patients at a tertiary care teaching hospital in Karnataka, India. Int. J. Contem. Med. Res., 3(8): 9-22.

8. Agarwal, S.G., Powar, R.M., Tankhiwale, S. and Rukadikar, A. (2015) Study of opportunistic infections in HIV-AIDS patients and their co-relation with CD4+cell count. Int. J. Curr. Microbiol. Appl. Sci., 4(6): 848-861. 
9. Dyab, A.K., Gaber, M.A., Hassan, T.M., El Kady, A.M., Badary, D.M. and Mahmoud, H.S. (2016) Parasites associated with human immune-deficiency virus (HIV) infection in Assiut university hospitals, Egypt. Madridge J. Vaccines, 2(1): 48-53.

10. Surekha, Y.A., Shilpa, H.S., Jeer, M. and Krishna, S. (2016) Intestinal parasites in HIV infected individuals and its correlation with the CD4 counts. Int. J. Curr. Microbiol. Appl. Sci., 5(2): 279-283.

11. UNAIDS. (2008) Report on the Global AIDS Epidemic. Joint United Nations Programme on HIV/AIDS, Geneva, Switzerland

12. Nissapatorn, V. and Sawangjaroen, N. (2011) Parasitic infections in HIV infected individuals : Diagnostic and therapeutic challenges. Indian J. Med. Res., 134(6): 878-897.

13. Khalil, P.S., Mirdha, B.R., Sinha, S., Panda, S., Singh, Y., Joseph, A. and Deb, M. (2015) Intestinal parasitosis in relation to anti-retroviral therapy, CD4+ T-cell count and diarrhea in HIV. Korean J. Parasitol., 53(6): 705-712.

14. Shilpa, H.S. and Mariraj, J. (2016) Intestinal parasitic infections in relation to HIV/AIDS status, diarrhoea and CD4 T-cell count. Int. J. Curr. Microbiol. Appl. Sci., 5(11): 523-531.

15. Vaillant, A.A. and Naik, R. (2020) HIV-1 Associated Opportunistic Infections. StatPearls Publishing, Treasure Island, FL.

16. Udeh, E.O., Obiezue, R., Okafor, F.C., Ikele, C.B., Okoye, I.C. and Otuu, C.A. (2019) Gastrointestinal parasitic infections and immunological status of HIV/AIDS coinfected individuals in Nigeria. Ann. Glob. Health, 85(1): 99.

17. Paboriboune, P., Phoumindr, N., Borel, E., Sourinphoumy, K., Phaxayaseng, S., Luangkhot, E., Sengphilom, B., Vansilalom, Y., Odermatt, P., Delaporte, E. and Etard, J.F. (2014) Intestinal parasitic infections in HIVinfected patients, lao people's Democratic republic. PLoS One, 9(3): 1-8.

18. Kiros, H., Nibret, E. Munshea, A., Kerisew, B. and Adal, M. (2015) Prevalence of intestinal protozoan infections among individuals living with HIV/AIDS at Felegehiwot referral hospital, Bahir Dar, Ethiopia. Int. J. Infect. Dis., 35: 80-86.

19. Solomon, F.B., Angore, B.N., Koyra, H.C., Tufa, E.G., Berheto, T.M. and Admasu, M. (2018) Spectrum of opportunistic infections and associated factors among people living with HIV/AIDS in the era of highly active anti-retroviral treatment in Dawro zone hospital: A retrospective study. BMC Res Notes, 11(604): 1-7.

20. Kindie, Y. and Bekele, S. (2016) Prevalence and risk factors for intestinal parasite infections in HIV/AIDS patients with anti-retroviral treatment in South West Ethiopia. J. Trop. Dis., 4(3): 1-4.

21. Chacin-Bonilla, L. (2017) Cyclospora cayetanensis. In: Rose, J.B. and Jiménez-Cisneros, B, editors. Global Water Pathogens Project. Michigan State University, UNESCO, Lansing, MI.

22. Stark, D., Barrat, J.L., Van Hal, S., Marriot, D., Harkness, J. and Ellis, J.T. (2009) Clinical significance of enteric Protozoa in the immunosuppressed human population Clin. Microbiol. Rev., 22(4): 634-650.

23. Faisal, A.F. and Bokhari, A.A. (2020) Microsporidium. StatPearls, Treasure Island, FL.

24. Aranzales, A., Radon, K., Froeschl, G., Pinzon, A. and Delius, M. (2018) Prevalence and risk factors for intestinal parasitic infections in pregnant women residing in three districts of Bogotá, Colombia. BMC Public Health, 18(1): 1071

25. Aneth, M. and Johnson, M. (2016) Prevalence of parasitic infections and associations with pregnancy complications and outcomes in Northern Tanzania: A registry-based cross-sectional study. BMC Infect. Dis., 16: 78 .

26. Pumipuntu, N. and Piratae, S. (2018) Cryptosporidiosis: A zoonotic disease concern. Vet. World, 11(5): 681-686.

27. Sanchez, R. (2010) Update on Cyclospora cayetanensis, a food-borne and waterborne parasite. Clin. Microbiol. Rev.,
23(1): 218-234.

28. Alfano-sobsey, E.M., Eberhard, M.L., Seed, J.R., Weber, D.J., Won, K.Y., Nace, E.K. and Moe, C.L. (2004) Human challenge pilot study. Emerg. Infect. Dis., 10(4): 3-5.

29. Robertson, L.J., Gjerde, B. and Campbell, A.T. (2006) Isolation of Cyclospora oocysts from fruits and vegetables using lectin-coated paramagnetic beads. J. Food Prot., 63(10): 1410-1414.

30. Alemu, G., Alelign, D. and Abossie, A. (2018) Prevalence of opportunistic intestinal parasites and associated factors among HIV patients while receiving ART at Arba Minch hospital in Southern Ethiopia: A cross-sectional study. Ethiop. J. Health Sci., 28(2): 148-159.

31. Liu, S., Roellig, D.M., Guo, Y., Li, N., Frace, M.A., Tang, K., Zhang, I., Feng, Y. and Xiao, I. (2016) Evolution of mitosome metabolism invasion-related protein in Cryptosporidium. BMC Genomic, 17(1): 1006.

32. Mohaghegh, M.A., Hejazi, S.H., Ghomashlooyan, M., Kalani, H., Mirzaei, F. and Azami, M. (2017) Prevalence and clinical features of Cryptosporidium infection in hemodialysis patients. Gastroenterol. Hepatol. Bed Bench, 10(2): 137-142.

33. Salehi, S.G., Mirjalali, H., Farnia, S. and Rezaeian, M. (2016) Prevalence of intestinal coccidial infections among different groups of immunocompromised patients. Iran. J. Parasitol., 11(3): 332-338.

34. Tandel, J., English, E.D., Sateriale, A., Gullicksrud, J.A., Beiting, D.P., Sullivan, M.C., Pinkston, B. and Striepen, B. (2019) Life cycle progression and sexual development of the apicomplexan parasite Cryptosporidium parvum. Nat. Microbiol., 4(12): 2226-2236.

35. Shrivastava, A.K., Kumar, S., Smith, W.A. and Sahu, P.S. (2017) Revisiting the global problem of cryptosporidiosis and recommendations. Trop. Parasitol., 7(1): 8-17.

36. Khurana, S. and Chaudhary, P. (2018) Laboratory diagnosis of cryptosporidiosis. Trop. Parasitol., 8(1): 2-7.

37. Haserick, J.R., Klein, J.A., Costello, C.E. and Samuelson, J. (2017) Cryptosporidium parvum vaccine candidates are incompletely modified with O-linked-Nacetylgalactosamine or contain $\mathrm{N}$-terminal $\mathrm{N}$-myristate and S-palmitate. PLoS One, 12(8): e0182395.

38. Bangoh, B., Voskuijl, J., Thitiri, W., Menting, S., Verhaar, N., Mwalekwa, L., de Jong, D.B., van Loenen, M., Mens, P.F., Berkley, J.A., Bandsma, R.H.J. and Schallig, H.D. (2019) Performance of three rapid diagnostic tests for the detection of Cryptosporidium spp. and Giardia duodenalis in children with severe acute malnutrition and diarrhoea. Infect. Dis. Poverty, 8(96): 1-8.

39. Garcia, L.S. (2002) Minireview laboratory identification of the Microsporidia. J. Clin. Microbiol., 40(6): 1892-1901.

40. Cali, A. and Takvorian, P.M. (2011) Microsporidiosis. In: Topics on the Pathology of Protozoan and Invasive Arthropod Diseases. Armed Forces Institute of Pathology, Washington, DC. p1-24

41. Agholi, M. (2013) HIV/AIDS-associated opportunistic protozoal diarrhea. AIDS Res. Hum. Retrovirus, 29(1): 35-41.

42. Rodriguez-morales, A.J. (2014) Protozoa: Cystoisospora belli (Syn. Isospora belli). In: Encyclopedia of Food Safety. Vol. 2. Academic Press, Cambridge, Massachusetts. p45-48.

43. Tom, B., John, B., Graeme, M. and Marc, M. (2012) Failure to eradicate Isospora belli diarrhoea despite immune reconstitution in adults with HIV a case series. PLoS One, 7(8): e42844.

44. Heelan, J.S. and Frances, W.I. (2002) Essentials of Human Parasitology. Delmar Publisher, New York.

45. Fayer, R., Esposito, D.H. and Dubey, P. (2015) Human infections with sarcocystis species. Clin. Microbiol. Rev., 28(2): 295-311.

46. Anderson, D., Nathoo, N., Lu, J.Q., KowalewskaGrochowska, K.T. and Power, C. (2018) Sarcocystis myopathy in a patient with HIV-AIDS. J. Neurovirol., 24(3): 376-378. 
47. Sadaf, H.S., Khan, S.S., Urooj, K.S., Asma, B. and Ajmal, S.M. (2013) Blastocystis hominis-potential diahorreal agent: A review. Int. Res. J. Pharm., 4(1): 1-5.

48. Chen, C.H., Sun, H.Y., Chien, H.F., Lai, H.S. and Chou, N.K. (2014) Blastocystis hominis infection in a post-cardiotomy patient on extracorporeal membrane oxygenation support: A case report and literature review. Int. J. Surg. Case Rep., 5(9): 637-639.

49. Wawrzyniak, I., Poirier, P., Viscogliosi, E., Dionigia, M., Texier, C., Delbac, F. and Alaoui, H.E. (2013) Blastocystis, an unrecognized parasite : An overview of pathogenesis and diagnosis. Ther. Adv. Infect. Dis., 1(5): 167-178.

50. Qadri, S.M.H., Al-Okaili, G.A. and Al-Dayel, F. (1989) Clinical significance of Blastocystis hominis. J. Clin. Microbiol., 27(11): 2407-2409.

51. Mcclelland, E.E., Casadevall, A. and Eisenman, H.C. (2007) Pathogenesis of Cryptococcus neoformans pathogenesis of Cryptococcus neoformans. In: New Insights in Medical Mycology. Springer, Netherlands. p131-157.

52. Kwon-Chung, K.J., Fraser, J.A., Doering, T.L., Wang, Z. and Janbon, G. (2014) Cryptococcus neoformans and Cryptococcus gattii, the etiologic agents of Cryptococcosis. Cold Spring Harb. Perspect. Med., 4(7): a019760.

53. Sungkanuparph, S., Tanphaichitra, D. and Pracharktam, R. (2003) Chronic diarrhea caused by Cryptococcus neoformans in a non-human immunodeficiency virus-infected patient. Scand. J. Infect. Dis., 35(3): 211-212.

54. Lieshout, L. and Roestenberg, M. (2015) Clinical consequences of new diagnostic tool for intestinal parasites. Clin. Microbiol. Infect., 21(6): 520-528.

55. Choi, T.I., Hong, E.J., Ryu, S.Y., Sim, C., Chae, J.S., Kim, H.C., Park, J., Choi, K.S., Yu, D.H., Yoo, J.G. and Park, B.K. (2018) Detection and identification of Sarcocystis cruzi (Protozoa: Apicomplexa) by molecular and ultrastructural studies in naturally infected Korean cattle (Bos taurus coreanae) from Daejeon, Korea. Korean $J$. Parasitol., 56(2): 121-127.

56. Hooshyar, H., Abbaszadeh, Z., Sharafati-Chaleshtori, R. and Arbabi, M. (2017) Molecular identification of Sarcocystis species in raw hamburgers using PCR-RFLP method in Kashan, central Iran. J. Parasit. Dis., 41(4): 1001-1005.

57. Natasa, T., Milenković, M., Vera, B., Dragan, Z. and Aleksandar, T. (2017) Blastocystis hominis: A mysterious and commonly disregarded parasite. Facta Univ. Ser. Med. Biol., 18(2): 39-47.

58. Martin, A., Brighente, K.B., Matos, T.A., Vidal, J.E., Hipólito, D.D. and Pereira-Chioccola, V.L. (2015) Molecular diagnosis of cryptococcal meningitis in cerebrospinal fluid: Comparison of primer sets for Cryptococcus neoformans and Cryptococcus gattii species complex. Braz. J. Infect. Dis., 19(1): 62-67.

59. Khademvatan, S., Masjedizadeh, R., Razin, E.Y., Mahbodfar,H., Rahim, F., Yousefi, E. and Foroutan, M. (2018) PCR-based molecular characterization of Blastocystis hominis subtypes in Southwest of Iran. $J$. Infect. Public Health, 11(1): 43-47.

60. Williamson, P., Jarvis, J.N., Panackal, A., Fisher, M.C., Molloy, S.F., Loyse, A. and Harrison, T. (2016) Cryptococcal meningitis: Epidemiology, immunology, diagnosis and therapy. Nat. Rev. Neurol., 13(1): 13-24.

61. Piranshahi, A.R., Tavalla, M. and Khademvatan, S. (2018) Genomic analysis of Blastocystis hominis isolates in patients with HIV-positive using locus SSU-rDNA. J. Parasit. Dis., 42(1): 28-33.

$* * * * * * * *$ 